\title{
Docência inovadora na universidade: percursos e princípios organizadores
}

\author{
Gionara Tauchen*
}

Daniele Simóes Borges**

\section{Resumo}

O presente artigo discute as experiências, as possibilidades e os princípios de inovação no ensino universitário. Para tanto, investiga-se a compreensão a respeito das inovaçôes e das práticas de ensino de seis professores atuantes nos cursos de licenciatura da área de Ciências da Natureza (Ciências Biológicas e Física) e de Pedagogia de uma universidade do sul do estado do Rio Grande do Sul, por meio da metodologia de investigação narrativa. Tal estratégia foi escolhida porque objetiva, em suas bases, o entendimento da ação docente. A partir das análises, o estudo aponta que a possibilidade de um ensino inovador inicia pelas inovaçóes no ensino. As narrativas revelam um esforço para a mudança do ensino universitário, manifestando emergências que subsidiaram a criação de quatro princípios de um ensino inovador: a interação e religação, o planejamento, a ação estratégica e a auto-hetero-avaliação.

Palavras-chave: Educação para a Inovação. Docência. Complexidade.

*Doutorado em Educação pela Pontifícia Universidade Católica do Rio Grande do Sul (PUC/ RS). Professora do Curso de Pedagogia e do Programa de Pós-Graduação em Educação e do Programa de Pós-Graduação em Educação em Ciências: Química da Vida e Saúde da Universidade Federal do Rio Grande (FURG).

**Mestre em Educação em Ciências: Química da Vida e Saúde pela Universidade Federal do Rio Grande (FURG). Professora substituta do Curso de Pedagogia da Universidade Federal do Rio Grande (FURG). 


\section{Inovações educacionais: percursos iniciais}

As inovaçôes no ensino podem ser interpretadas como açōes educativas que são desenvolvidas em diferentes situaçôes, provocando mudanças no processo ensino-aprendizagem. Nesse sentido, o inovar constitui-se em como um fenômeno que necessita ser compreendido a partir de um olhar multirreferencial ${ }^{1}$ sobre o contexto histórico e temporal da ação estudada. Para tanto, é preciso uma leitura plural e também "[...] de um pensamento que considere as partes em sua relaçáo com o todo e o todo em suas relaçóes com as partes" (MORIN, 2011a, p. 46), visando compreender para além das transparências do fenômeno; adentrando as suas opacidades (MARTINS, 1998).

No Brasil, os estudos sobre inovaçóes educacionais ganharam maior incidência com Garcia (1980), ao adentrar o conceito de inovação. Dessa forma, organizou um livro com a contribuição de outros autores, que, também, vinham explorando a temática. Dentre esses, salientamos as pesquisas de Krasilchik (1980), em torno da inovação no ensino de Ciências, e as de Ferretti (1980), que busca a compreensão da inovação na atividade pedagógica, entre outros temas. Destacam-se, também, as obras de Farias (2006) e Zanchet (2009), os quais desenvolveram trabalhos sobre as inovações no cenário da escola. No âmbito das pesquisas relativas à inovaçáo na universidade, destacam-se Cunha (1997, 2001a, 2001b, 2005), Franco e Morosini (2006), e Morosini (1997) apresentando contribuiçóes no que diz respeito à aula universitária. As autoras tratam a inovaçáo como ruptura com o modo tradicionalmente conferido pela epistemologia positivista. Sendo assim, a inovação se localiza na transposição de uma perspectiva didática transmissiva, orientada pela racionalidade técnica, por uma perspectiva emancipatória capaz de abranger a reconfiguração dos saberes, a participaçâo dos discentes nas decisóes pedagógicas e a experimentação de novas metodologias e estratégias de ensino. Cabe apontar, também, os estudos de Masetto $(2004,2011)$ nos quais, as inovaçóes se localizam, principalmente, a partir da aquisição de uma postura mediadora e problematizadora do professor no desempenho das suas práticas pedagógicas. Da mesma forma, não podemos deixar de citar os estudos da argentina Lucarelli $(2000,2009)$. A autora tem realizado pesquisas em parceria com pesquisadores brasileiros, e em seus trabalhos, lança inúmeras discussões para ampliar a compreensão sobre a inovação educacional.

Sobressaem-se, na América do Norte, as pesquisas de Fullan e Hargreaves (2000) e Christensen, Horn e Johnson (2012), que apresentaram importantes e 
distintas consideraçôes sobre a historicidade do conceito de inovação e algumas perspectivas com relação ao conceito de mudança educativa.

No contexto Europeu, encontramos uma vasta produção de pesquisas sobre inovação. Destacam-se os trabalhos de Huberman (1973), Hassenforder (1974), Hernandez (2000), Rasco (2000), Thurler (2001), Carbonell (2002) e Murillo (2007), com os quais temos dialogado, tendo em vista suas contribuiçōes para nossos estudos.

Em todos esses trabalhos, percebe-se um consenso: a inovação, por mais que seja um termo complexo que exprima diferentes denotaçóes, sendo dependente do outro para ser validada e do seu contexto-espaço para ser compreendida, é apresentada, muitas vezes, como um acontecimento que acarreta uma melhoria no sistema educativo. É importante ponderar que é recorrente nos trabalhos o sentido de qualidade entrelaçado em entendimentos de inovação. Notamos, também, que a inovação no ensino não se restringe à técnica, mas a incorpora, pois os estudos defendem a ideia de reforma na episteme da prática educativa e de ruptura com o paradigma de ensino tradicional.

Por vezes, os autores mencionados abordam a inovação como sinônimo de mudança e de reforma. Porém, Farias (2006) alerta que esses são conceitos diferentes, pois, uma vez em um processo de inovação, a mudança torna-se uma possibilidade ou, até mesmo, uma oportunidade para ressignificação da prática docente, não um sinônimo de inovação. Todavia, é importante alertar que inovação e mudança interagem; ambas têm como objetivo comum a melhoria da qualidade do ensino e da educação.

Para Carbonell (2002), o desenvolvimento da inovação, pelo professor, tende a acontecer quando este exerce sua prática com paixão e compromisso pelo magistério, objetivando constituir uma ação educativa mais fluida entre professor, conteúdo e aluno. Por isso, salientamos que uma ação inovadora não é algo que ocorre involuntariamente. O professor inovador, de algum modo, pensa, reflete e planeja sua interação com o conteúdo e para/com os alunos, ou seja, não há inovação sem intencionalidade. Nesse sentido, acreditamos que a inovação tem, em seu cerne, o princípio de reorganizar o processo educativo por meio de suas interretroaçóes (MORIN, 2007).

É notável, ainda, a relação entre a inovação educacional e a formação de professores, pois, uma vez estabelecidas inovaçóes no ensino, por meio do corpo docente, as possibilidades de um ensino inovador sáo maiores. No 
que diz respeito à instituição escolar, por exemplo, o Brasil tem proposto, em suas políticas educacionais, projetos ditos inovadores, porém com características verticais e unilaterais. Logo, o sucesso desses projetos é escasso, posto que a inovação tem como pilares a contextualização, o planejamento, a intencionalidade, a reflexão. Ou seja, é composta por uma rede de referências e ações.

Com relação à inovação no ensino universitário, foco deste trabalho, os estudos ${ }^{2}$ trazem, em seus resultados, problematizações sobre os processos de inovação na aula universitária no âmbito institucional, nas experiências curriculares e nos projetos pedagógicos. Com base nesse cenário, questionamos: quais são os movimentos que levam os professores a inovar? $\mathrm{O}$ que os professores pensam sobre a inovaçáo? Que fatores desencadeiam as inovaçóes? Como realizar a gestão da inovação no Ensino Superior? Como avaliar as inovaçôes? Quais os elementos que permeiam a organização de um ensino inovador? A partir desses questionamentos, organizamos o presente estudo ${ }^{3}$, objetivando compreender as concepçóes, as experiências e os princípios que potencializam as inovaçóes no ensino universitário.

\section{Abordagem metodológica}

Nesta pesquisa, de natureza qualitativa, buscamos adentrar no "[...] tecido de acontecimentos, açóes, interaçóes, retroaçóes, determinaçóes, acasos, que constituem nosso mundo fenomênico" (MORIN, 2007, p. 13) e que perpassam as inovaçóes no ensino. Estamos, nesse sentido, reconhecendo os professores como criadores de inovaçóes em seus processos de ensino, em seus contextos particulares e institucionalmente compartilhados. A intenção metodológica é compreender a complexidade dinâmica das trajetórias, das experiências e das histórias, as quais têm constituído as práticas educativas dos sujeitos pesquisados. Para dar conta dessa intenção, optamos pela metodologia de investigação narrativa, pois esta tem, em suas bases, o objetivo do entendimento da experiência docente (CLANDININ; CONNELLY, 2000).

Telles (2002), em seus estudos sobre investigação narrativa, pondera que, nessa metodologia, os professores não devem ser interpretados como agentes produtores de dados para a pesquisa. Pensamos igualmente e consideramos cada participante da pesquisa como "[...] um ser sabente de sua prática pedagógica e dotado de um potencial e capacidade para a reflexáo" (TELLES, 2002, p. 97). 
Nessa perspectiva, “[...] o papel do pesquisador adquire a dimensão de mentor que orienta, reflete e discute juntamente com um professor participante e agente na construção do conhecimento sobre sua prática pedagógica - um professor pesquisador" (TELLES, 2002, p. 98).

Tendo como base essas compreensóes, sete professores universitários foram convidados a participar desta pesquisa. O convite foi realizado levandose em consideração dois aspectos: os resultados de um estudo, antecedente, que tinha como objetivo identificar, na percepção dos formandos, quais práticas inovadoras no ensino superior haviam sido desenvolvidas nos cursos de licenciatura nas áreas das Ciências da Natureza (Ciências Biológicas e Física) e na da Pedagogia, em uma universidade federal do sul do estado do Rio Grande do Sul; e a indicação dos nomes dos docentes dessa instituição considerados inovadores pelos alunos, bem como os motivos que conferiram a esses o reconhecimento de inovaçóes no ensino.

A partir dessas indicaçóes, entramos em contato com os professores mais citados, convidando-os a participar da pesquisa e propondo-lhes a elaboração de uma narrativa que expressasse suas experiências de inovação no ensino, com o intuito de buscar, em sua memória pedagógica, a (re)construção das suas experiências formativas e docentes. Entendemos que o professor, por meio dessa metodologia, tem a possibilidade de elaborar seu discurso, o qual, nesta pesquisa, será nomeado de histórias de situaçōes de ensino-aprendizagem, pois, "[...] no sólo mostrará los momentos de éxito o de final feliz, sino que reconstruirá todo ese camino, esa aventura, y también esas desventuras, que hicieron posible que esta experiencia les pertenezca y los/as identifique, los/as cuente en pequeñas historias" (SUÁREZ; OCHOA; DÁVILA, 2004, p. 11).

$\mathrm{O}$ corpus da análise constituiu-se de um conjunto de seis histórias. Para isso, adotamos a seguinte orientação: a) leitura cuidadosa das histórias; b) identificação das temáticas e dos significados narrado; e, c) agrupamento das temáticas (CLANDININ; CONNELLY, 2000; TELLES, 2002). Os professores também foram identificados por pseudônimos: Professor Texturado, Professor Correntinha, Professor Entrelaçado, Professor Jaspé, Professor Penteado, Professor Bouclé. Utilizamos esta denominação por analogia aos fios que tecem o complexo tecido das inovações no ensino.

Dessa forma, propusemo-nos a compreender os sentidos das concepçóes e açóes desses professores, bem como as suas interrogaçóes, por vezes, explícitas; em outras situações, implícitas em suas escritas narrativas. Segundo Larrosa 
(1996), a narrativa oportuniza a compreensão das práticas educativas como lugares, os quais se produzem, interpretam-se e medeiam-se histórias, sempre polifônicas, de situaçốes vividas em sala de aula. Desse modo, as histórias, aqui apresentadas, não serão homogêneas. Por mais que a experiência educativa carregue certas características globais, a narrativa funciona como um mecanismo de compreensão das particularidades e como "una narración está siempre inacabada, de que las historias será re-contadas una y otra vez, y de que las vidas serán re-vividas de formas nuevas" (CONNELLY; CLANDININ, 1995, p. 40). Logo, as histórias analisadas assumem um discurso identitário que nos possibilitou a interpretação dos diferentes papéis que a inovação tem assumido na prática desses docentes universitários, possibilitando anunciar alguns princípios universais ao ensino inovador.

\section{Enlaçando os fios para a composição do tecido}

O enlace dos fios, para a composição desse tecido que expressa a docência inovadora, foi elaborado a partir das narrativas dos professores, revelando algumas particularidades do fenômeno estudado. Entre os seis professores inovadores apresentados neste estudo, dois têm licenciatura e bacharelado; três têm licenciatura; e um tem somente o bacharelado. Em seus processos de formação, mestrado e doutorado, três atuaram na área das Ciências da Natureza; os demais têm em seus processos de formaçáo, mestrado e doutorado, na área das Ciências Humanidades, mais precisamente no campo da Educação, Educação em Ciências e Ensino de Física. Tal quadro nos apresentou notável complexidade, pois pensávamos que a eficiência ou a qualidade do processo educativo estivesse associada aos saberes e à formação no campo das Ciências Humanas, mais especificamente a compreensão científica dos conhecimentos pedagógicos construídos por meio da formação em curso de licenciatura.

Nesse sentido, Prigogine (1996, p. 14) já anunciava que "assistimos ao surgimento de uma ciência que não mais se limita a situaçóes simplificadas, idealizadas, mas nos póe diante da complexidade do mundo real". Por isso, a necessária reforma do pensamento (MORIN, 2011b) está em compreender que "[...] todo conhecimento científico-natural é científico-social” (SANTOS, 2002, p. 89). Logo, "a superaçẫo das ciências naturais/ciências sociais tende assim a revalorizar os 'estudos humanísticos'. Mas esta revalorização não ocorrerá sem que, as humanidades sejam, elas também, profundamente transformadas" (SANTOS, 2002, p. 93). 
Morin (2011b, p. 41) também vai ao encontro de Santos (2002), ao afirmar que as ciências humanas também estão, em parte, "[...] desligadas, fragmentadas e compartimentadas". Assim, a transformação das humanidades passa, impreterivelmente, pela reforma do pensamento, visando uma percepção da complexidade psicológica, biológica e cultural do homem propondo uma religação dos saberes (MORIN, 2004). Daí a emergência de "[...] uma ruptura fundante com a possibilidade de uma só forma de conhecimento verdadeiro" (SANTOS, 2003, p. 35). Conforme expressa Morin (2005, p. 31), "[...] tratase de estabelecer a relaçáo entre ciências naturais e ciências humanas, sem as reduzir umas às outras (pois nem o humano se reduz ao biofísico, nem a ciência biofísica se reduz às suas condiçôes antropossociais de elaboração)”.

Se o paradigma moderno instituiu e separou o que é do homem e o que é da natureza (SANTOS, 2003), encontramos substratos na epistemologia da complexidade que nos ajudam a superar essa premissa. Sendo assim, o fenômeno da educação necessita ser compreendido como uma função social global. Por isso, a disjunção dos campos das ciências naturais e sociais geram uma relaçáo dual e, portanto, regressiva.

A situação exprime uma afirmação: um professor que tem sua itinerância formativa no campo das Ciências da Natureza não é mais ou menos capaz de promover inovaçóes no ensino do que um professor que tem sua constituição no campo específico da educação. Essa percepção aponta para a "[...] superação da fronteira entre o estudo do ser humano e o estudo da natureza" (SANTOS, 2002, p. 67). Ademais, toda a natureza é social e todo homem é um ser natural, ou seja, o estudo dos fenômenos humanos e educativos não deveria ser reduzido à dicotomia entre as Ciências da Natureza e Ciências Sociais. Ao assegurar isso, não queremos desconsiderar que os campos têm marcas, particularidades e objetivos próprios, mas, no que concerne a ação educativa propriamente dita, o professor inovador rompe com uma concepção tradicional de ensinoaprendizagem disciplinar que polariza, que dissipa, que separa e que classifica o conhecimento.

O professor inovador não é unirreferencial ${ }^{4}$. É, sobretudo, expressão das atividades e das atitudes que construiu a partir de um processo complexo de inter e retroação com sua experiência; é "[...] um sujeito capaz de aprender, inventar e criar 'em' e durante o seu caminho" (MORIN; CIURANA; MOTTA, 2003, p. 18). Desse modo, inspiradas no pensamento complexo, que se "[...] apresenta com traços inquietantes do emaranhado, do inextricável, 
da desordem, da ambiguidade, da incerteza [...]" (MORIN, 2007, p. 13), iniciamos esta tessitura, que é incerta e difícil, pois nos mostra os limites do nosso próprio conhecimento expresso entre os enredos e as tramas dos fios que aqui buscamos tecer.

As noções de formação, de trajetória e de docência se entrelaçam quando buscamos compreender o professor como "sujeito de sua própria vida e do processo educativo do qual é um dos atores" (ISAIA, 2003, p. 241), pois os aspectos pessoais e profissionais são mobilizados e se inter-relacionam em seus pensamentos e açóes. Partimos do pressuposto de que a vida humana se constitui por meio das interaçóes entre as dimensóes espirituais, linguísticas, sociais, políticas, culturais e ecológicas. Por isso, somos multirreferenciais. Logo, o desenvolvimento pessoal e profissional que se organiza ao longo de um percurso, que vai desde a sua historicidade, a opção pela profissão, até os espaços institucionais em que a atividade se desenvolve, está marcado pelos sentidos e significados que o individuo atribuiu ao mundo e a si mesmo. A trajetória representa a temporalidade dos processos formativos que, no caso dos professores inovadores, foi estruturada em percursos institucionais, os quais influenciaram e condicionaram suas açôes formativas (ENRICONE; GRILLO, 2005; ISAIA, 2003; OLIVEIRA, 2003). Estas, por sua vez, são mobilizadas nas atividades que envolvem o exercício da docência: saberes, fazeres, atitudes, sentimentos, entre outros.

Conforme expressa Isaia (2003, p. 245), a docência universitária “[...] apoia-se na dinâmica interação de diferentes processos que respaldam o modo como os professores concebem o conhecer, o fazer, o ensinar e o aprender, bem como o significado que dão a eles", como expressa a seguinte narrativa do Professor Bouclé:

Durante meus cinco anos de graduação, tive a oportunidade de ser bolsista [...], no qual estava imersa com o pensar e o agir na busca de um ensino de ciência e biologia significativo e contextualizado. Minha atuação ocorria através da elaboração e desenvolvimento de oficinas para alunos da rede de ensino do município, produção de materiais paradidáticos, participação em projetos, enfim foram muitas as experiências e saberes construidos neste tempo de bolsista. 
Essa narrativa expressa que a experiência docente é um acontecimento complexo, porque se dilata, não apenas das ações na dimensão do ser uno e do ser múltiplo, mas pelo conjunto das ações e dos ecos da e na vida. Ou seja, por meio das vivências, das incertezas, das certezas, dos exemplos, dos modelos, do lógico, do contraditório, do real e do imaginário (MORIN, 2011b). Da experiência construída no percurso de uma autoformação que se regenera nas relaçōes teórico-práticas, construímos nossas referências docentes. Logo, o professor de outrora, mediando experiências que ecoaram significativamente nos discentes, influenciou o interesse desses pela docência. Da mesma forma, fizeram-no as vivências sociais, políticas e educativas marcadas pelo envolvimento e compromisso com o outro, conforme narrado pelo Professor Entrelaçado:

Outro ponto que vale a pena destacar, e também pode caracterizar inovaçáo, é o fato da minha intensa atividade no movimento estudantil enquanto estudante. Lembro-me tão bem das reivindicaçóes estudantis e destaco tanto a relevância do papel político do estudante que de alguma forma me aproximo deles por isso e também avanço na conquista da confiança dos estudantes. De alguma forma, a intensidade das atividades que vivi neste meio faz com que eu ainda me sinta um deles.

É possível inferir, na pesquisa realizada, que as experiências significativas dos professores decorrem de processos formativos que têm integrado suas trajetórias institucionais, tanto na condiçâoo de estudante, quanto na de docente. Configurase, assim, uma "cultura docente em ação" (OLIVEIRA, 2003, p. 260). Ou seja, "[...] a formação do docente universitário é um campo de silêncio na legislação, que dele exige apenas competência técnica, o que evidencia a ausência de uma política diretamente voltada para a formação de professores universitários" (PEIXOTO, 2010, p. 523), recaindo as influências sobre as ações docentes nos processos de socialização profissional e nas experiências significativas.

Percebemos, também, que a experiência é acionada na construção da autonomia pedagógica do professor, que se estrutura, na perspectiva da complexidade, na sua dependência externa:

Conversei com o coordenador do curso na época e ele me enviou a ementa da disciplina. Percebi, na leitura desta ementa, que a mesma era extremamente ampla, podendo dar 
liberdade ao trabalho do professor [...]. Passei aquele verão preparando material para a disciplina, assim como diversas atividades espelhando-me naquelas que eu havia cursado quando no curso de graduação. (Professor Texturado).

Ao refazer o caminho da constituição docente, percebemos o quanto os contextos foram tramando suas formaçôes: a vivência como graduandos; o envolvimento com as atividades de ensino-pesquisa-extensão e com os movimentos sociais; a chegada ao ensino superior. Pimenta (1997), ao discutir os saberes da docência, pondera que os professores se formam a partir das necessidades e desafios da prática de ensino, ou seja, formam-se por meio dos seus saberes da experiência que, ao serem tratados reflexivamente, sustentam suas hipóteses, teorias e concepções de ensino. Assim, a relação que o professor estabelece com o exercício da docência é constituído e constitui suas experiências teórico-práticas. Não há teoria de um lado e prática de outro, conteúdo ou forma, meio ou fim, mas um "circuito vivo onde tudo é, simultaneamente, meio e fim” (MORIN, 2005, p. 316).

Ainda, no que tange os elementos que permeiam o exercício da docência, tiveram destaque a autoavaliação, a recursividade e a reflexão na ação docente. Os professores inovadores expressam esses princípios na organização e planejamento da ação educativa, conforme evidenciamos:

Sobre o planejamento. Parto da ementa da disciplina. Tenho um conjunto de habilidades indicado nessa ementa. Estruturo-me em um cronograma por bimestre. Cada aula tem um tópico previsto. Como vou desenvolvê-lo, ai eu preciso conhecer a turma. [...] É um movimento que depende da turma [...]. Procuro preservar o cronograma do bimestre, mas o recurso didático a ser utilizado depende da turma e do andar das atividades. (Professor Correntinha).

A forma como os alunos reagem às minhas técnicas didáticas são aportes fundamentais para o meu aperfeiçoamento como professor. Recebo com o maior prazer às criticas dos meus estudantes porque faço delas estratégias para melhorar a cada aula a minha didática. (Professor Entrelaçado). 
Pérez Gomes (1995, p. 104, grifo do autor) afirma que, "quando o profissional se revela flexível e aberto ao cenário complexo de interacçôes da prática, a reflexão-na-ação é o melhor instrumento de aprendizagem". A atenção do professor em ouvir o estudante e perceber suas inquietaçóes, amarradas em sua própria autopercepção, projetam a auto-eco-(re)organização permanente da ação.

Assim, o planejamento tem sua qualificação regulada pela ação e pela percepção dos envolvidos no processo de ensino-aprendizagem, ou seja, este retroage sobre aqueles, conforme expresso na narrativa que segue. Essa narrativa exemplifica, de forma particular, a ação de um docente, mas seu conteúdo manifesta-se, também, nas narrativas dos demais sujeitos da pesquisa.
Na primeira semana de aulas, fiz a tradicional apresentação e sentei com os alunos para uma conversa sobre como se sentiam enquanto formandos. Tive uma surpresa ao receber respostas sobre o temor do estágio, a falta de conhecimento da sala de aula, a falta de conhecimento (minimo) das politicas públicas. Sai daquela aula com uma inquietação, passei o resto do dia pesquisando os impactos das politicas públicas na Física. Ao final do dia, havia trocado completamente o foco que queria dar àquela disciplina. Pela primeira vez eu me deparava com a situação de ser professor e precisar auxiliar os alunos em sua formação. Neste dia, descobri os princípios que norteariam meu trabalho na Licenciatura a partir de então: multidisciplinaridade, contextualização, desenvolvimento de competências. (Professor Texturado).

Nessa perspectiva, o planejamento educacional não se reduz a um programa ou ao ordenamento da açáo docente. O planejamento expressase como ação estratégica ${ }^{5}$, comportando os acontecimentos decorrentes das interaçôes, as incertezas e, também, a ordem. Assim, as estratégias, manifestas por meio das diferentes metodologias de ensino, também são destacadas pelos professores como mecanismos de regeneraçáo da atividade docente:

[...] creio que para o ensino ser inovador ele deve explorar recursos ou formas de interação que o licenciando utilizará em sala de aula. Aprender a utilizar determinados recursos, 
seja o computador, seja um experimento diferenciado, seja uma abordagem diferente da tradicional. Ao propor a utilização das PCN+, pude apresentar ao estudante que ele poderia criar sua abordagem para ensinar fisica, com o foco na motivação do estudante para aprender a ciência, neste caso com a contextualização do assunto. [...] Afinal, devemos nos manter em constante mudança, e esta deve buscar sempre o novo. Ai vem a inovação, e o ciclo recomeça! (Professor Texturado).

A tecnologia também é destacada como um elemento fortemente vinculado aos processos de inovação no ensino. É perceptível, na fala anterior, que a tecnologia está contribuindo com a alfabetização científica permanente dos estudantes. Ou seja, o aprender como manusear e como utilizar recursos vinculados à rede tecnológica "[...] alarga consideravelmente o campo do cognoscível, isto é, o campo do que pode ser visto, percebido, observado e concebido" (MORIN, 2005, p. 64), oportunizando a exploração de outras formas e leituras para a mediação dos conteúdos de ensino.

Destacam-se, também, as orientaçóes curriculares, que subsidiam a construção dos conhecimentos para análise e estudo da ação do futuro docente. Nos cursos de licenciatura, sabemos que o conhecimento dos Parâmetros Curriculares Nacionais (PCNs), por parte dos docentes e dos licenciandos, auxilia no planejamento para os estágios curriculares no Ensino Fundamental e Médio. O contato com as orientações, ainda na graduação, permite uma leitura e interpretação crítica desse material, que tem orientado princípios e regulaçóes curriculares para a educaçáo nacional.

Assim, as narrativas expressam as estratégias e os recursos metodológicos que estão em evidência na aula universitária: o uso do computador, dos Parâmetros Curriculares Nacionais (PCNs), do livro didático do ensino básico, das atividades experimentais e o do roteiro de estudos, conforme assevera a narrativa do Professor Jaspé:

Um primeiro ponto importante é que, nas disciplinas integradoras, sempre utilizo vários livros didáticos de ensino fundamental e médio nas aulas, procurando destacar principalmente o que cada um tem de inovador, de bom, de especial, como são felizes ao abordar certo conteúdo, que 
exemplos interessantes utilizam, que situaçöes exploram a contento. Tento também destacar como um livro difere do outro, como divergem, que ênfase curricular cada um adota, isto é, que conjunto coerente de mensagens sobre ciências são comunicadas, explícita ou implicitamente, ao estudante pelo livro. Um segundo aspecto que trabalho bastante nas Atividades são os experimentos. Como a física é uma ciência intrinsecamente experimental, sempre me interessei pela experimentação no ensino de física. É um fato que poucos professores realizam atividades experimentais nas escolas, levando os estudantes a uma visão distorcida da ciência, em que associam física à teoria e a desconectam das aplicaçooes tecnológicas, intimamente ligadas à fisica experimental [...]. Um terceiro aspecto é o uso do computador nas aulas de Física. Nesse sentido, tenho procurado utilizar, no ensino de fisica, softwares e applets.

O uso do computador expressa o quanto a ciência, a tecnologia e a educação estáo vinculadas. Nesse sentido, numa tendência complexa, a interaçáo ciência-tecnologia-educação é essencial para superação das relações simplificadoras, lineares e dicotômicas que disjuntam o homem/natureza, sujeito/objeto, objetividade/subjetividade, ciência/tecnologia (MORIN, 2005).

Consideramos que as atividades citadas pelos professores pretendem oportunizar o espaço da construção, do questionamento, do diálogo e do debate em aula. Concretamente, a experimentação, salientada também em algumas narrativas, é uma atividade que permite que os estudantes, ao terem contanto com outras possibilidades, desenvolvam a imaginação e o raciocínio. Além disso, a experimentação permite que os alunos construam compreensões particulares acerca dos fenômenos estudados (LABURÚ; MAMPRIN; SALVADEGO, 2011). Por isso, vale a pena advertir que a experimentaçáo expressa nas narrativas se afasta de princípios indutivistas e da pura busca pela verificação, ou seja, estão distantes de um conhecimento simplificador (MORIN, 2005). Os professores vinculam a experimentação a outras vivências para as situaçóes de ensino, tornando, assim, uma atividade mais de investigação e interpretação teórico-prática e de motivação, conforme a narrativa do Professor Jaspé: "[...] sempre proponho e revisito vários experimentos com os licenciandos, procurando 
motivá-los e dar-lhes subsidios concretos para que possam adotar a experimentação como um dos pilares de seu futuro fazer docente".

Outra estratégia de mobilização e interação entre os alunos e os conteúdos de ensino são os roteiros de estudos, os quais oportunizam uma organização diferenciada para a rotina da aula. Estes demandam outros modos para ensinar os conteúdos conceituais, procedimentais e atitudinais:

Desta forma, eu utilizo o periodo inteiro de uma das quatro aulas para fazer um estudo dirigido, chamado por mim de roteiro de estudo, relativo aos conteúdos ministrados durante a aula teórica deste mesmo dia. [...] Esse momento é exatamente aquele utilizado por mim para sentar lado a lado com os estudantes, olhar nos olhos deles, fazer esquemas e explicar no caderno deles as dúvidas das aulas e também para conversar assuntos náo relacionados à aula, como música, politica, atividades cotidianas e qualquer outro assunto. Não é meu objetivo medir o que eles aprenderam em aula, mas sim complementar a aula explicando de perto, corrigindo o que eles não entenderam e, principalmente, me aproximando deles para que eles confiem em mim e para que eu também possa aprender com eles. Não demora mais do que um mês para que eu saiba o nome de todos de uma sala de 40 estudantes e para que eu já possa me considerar amigo deles. Costumo dizer que a cada ano faço 80 novos amigos, pois em média este é o universo de estudantes que convivo na graduação. Eu sinceramente adoro o roteiro de estudos. (Professor Entrelaçado).

A partir do envolvimento do professor com sua disciplina é que vão se desenrolando as características do ato de ensinar. Notamos, com o professor Entrelaçado, sua habilidade em estabelecer um grupo de estudos em sala de aula, visto que este incentiva a experiência de aprendizagem partilhada com o outro, ao fazer do diálogo um princípio articulador da aprendizagem. Conforme constata Cordeiro (2010, p. 24, grifo do autor),

há certamente maneiras diversas de ensinar, poderíamos dizer mesmo, diferentes estilos de ensinar. O sucesso deste ou 
daquele estilo depende, muitas vezes, não apenas do saber técnico e pedagógico acumulado pelo professor mas também de determinadas características de personalidade de cuja variedade resultam os diferentes tipos humanos.

O autor indica também que nenhuma escolha de método didático é inocente, pois a intencionalidade do professor está pautada em seus objetivos educacionais. Portanto, em alguma medida, toda e qualquer ação de ensinar tem um fundamento epistemológico.

Na narrativa do professor Penteado, percebemos outra intencionalidade. O professor demonstra preocupação em buscar a proximidade com o contexto sociocultural do estudante, tratando, assim, temas e situaçóes associados ao exercício da docência como, por exemplo, o trabalho com o livro didático da Educação Básica:

Outra coisa que eu trabalhava com eles era o livro didático do ensino básico. Depois de estudar um tema de estudo, sistema cardiovascular, por exemplo, solicitava que lessem o livro didático do ensino e depois discutia com eles se o livro estava bem ou não, o que estava faltando, o que o professor poderia fazer a mais, o que eles poderiam, dentro de sala de aula, discutir sobre aqueles assuntos [...]. (Professor Penteado).

Assim como o trabalho com os PCNs, o estudo sobre o livro didático da Educação Básica representa a preocupação dos professores em contextualizar a atividade docente e as possibilidades no cenário educacional. Dessa maneira, os docentes estão fomentando estratégias para que seus estudantes exercitem sua inteligência cognitiva, para que, como consequência, desenvolvam capacidades e habilidades de um pensar e de um aprender que problematizam a razão, os desafios vitais, mortais e morais. Tal preocupaçáo promove a inovação no modo de ensinar desses professores, pois estão se permitindo articular outros saberes, outras linguagens e outras interpretações, a partir de "[...] um princípio de acção que não ordena mas organiza, que não manipula mas comunica, que não dirige mas anima" (MORIN, 2008 p. 353).

Os princípios metodológicos apresentados pelos professores revelam as ideias de reflexividade e auto-hetero-avaliaçấo como construtoras das compreensōes do professor em, durante e após a ação. Esse entendimento 
parte de uma compreensão recursiva do ensino, em que o professor que ensina também aprende, ou seja, o professor se auto-eco-produz na ação didática.

Entendemos que é a partir desses movimentos que se intenciona e se expressa a inovação, uma vez que se "[...] produz criação e desconstrução das regulaçôes anteriores" (MACEDO, 2010, p. 96). Ou seja, a prática tem por base um planejamento composto por teoria, criatividade, imprevistos e avaliação. Dentro disso, localizam-se o já acontecido e o já compreendido, bem como a incerteza e a desordem. No que perpassa nossa compreensão de incerteza, corroboramos com Morin (2011a, p. 244), quando este expressa que "[...] existe, então, um princípio de incerteza que não se pode impedir e que deve nos tornar conscientes de que o que sempre fazemos é apostar. Não se pode prever o sentido da nossa ação a longo prazo, pois existe uma lei de imprevisibilidade total".

A interação entre os diferentes fatores, que interferem no processo do planejamento, até no desenvolvimento em aula, torna-se impossível de ser uniforme, universal ou fechada. A inovação no ensino é um movimento de criatividade e geratividade dentro do processo que denominamos de planejamento educacional: é constituída pelas noçóes de sistema, interação, organização, ordem, desordem, ser e existência (MORIN, 2005).

Assim, o planejamento ancora-se na auto-hetero-avaliaçáo do estudante e do professor, a qual promove as regulaçóes dos processos. Mas como a autohetero-avaliação vem acontecendo?

Como uma das formas de avaliação, utilizo o portfólio reflexivo e no mesmo percebia, nos registros doslas acadêmicos/as, quando uma aula tinha sido "diferente", ou seja, tinha sido significativa, instigante e motivadora. Assim, considero de fundamental importância aulas "diferentes", desde que essa diferença seja marcada pelo fato dessa aula ser potencializadora de construção de outros significados, aprendizagens, reflexōes e motivaçôes relacionadas a educação, ao ato de ensinar e aprender. (Professor Bouclé).

Depois ao final de ciclos de assunto, realizo produçóes maiores e com expectativa de maior reflexão. Penso que a utilizar na avaliação um trabalho "completo" como um artigo ou um 
projeto os deixa satisfeitos, pois estão cansados de resumos ou leituras espaçadas (Professor Correntinha).

Cada professor tem elementos distintos para organizar o processo de avaliaçáo do ensino, mas os mecanismos utilizados se afastam da intencionalidade classificatória e quantitativa que perpassa, tradicionalmente, a avaliação no ensino superior (LÜDKE, SALLES, 1997). Além disso, há diversificação das estratégias e instrumentos de avaliação. O que notamos é a preocupação dos professores em fazer do processo de avaliaçáo uma atividade qualitativa para o percurso de aprendizagem do estudante e da sua própria atividade docente. Outro aspecto é o incentivo à escrita reflexiva. Os professores, ao apresentarem propostas de desenvolvimento do pensamento crítico do aluno, estão estimulando a autoavaliação, afastando-se de uma avaliação pautada na verificação, ao privilegiar a descoberta, a construção de saberes e, também, a autocrítica e o autoexame.

Ainda, dessas narrativas, destaca-se a preocupação do professor com o bem-estar do estudante que parte da interação, não apenas, de um técnico ou de um mestre para/com um aprendiz, mas com um formador estratégico e, por isso inovador, que busca estabelecer na atividade de ensino uma dialógica, crítica e respeitosa. Assim, "[...] o ensinar transforma-se em incentivar, instigar, provocar, talvez desafiar. Na verdade, ensinar algo é sempre desafiar o interlocutor a pensar sobre algo" (CASTRO, 2001, p. 19), conforme expressa o professor Entrelaçado:

Neste sentido, pensando que o ensino é um processo que resulta da interação do estudante e do professor, qualquer ação que provoque um fluxo maior de saberes entre estudante e professor, nas duas vias, bem como entre estudantes, faz com que todos os envolvidos nestas interaçôes ganhem em experiência, conhecimento e saiam todos melhores do que entraram na sala de aula, caracterizando um processo inovador.

Ensinar é uma função complexa, pois a comunicação do sistema didático não é garantida. Ao contrário, na relação interpessoal, há necessidade de firmar acordos respeitosos e afetivos. Dizemos isso porque acreditamos que a sala de aula, como um espaço de imprevisibilidade, torna-se inovadora quando a capacidade social do professor, no sentido ético e intelectual, possibilita a 
manifestação da multidimensionalidade dos sujeitos. Ou seja, a face solidária, a face afetiva do professor, firma a existência de uma unidade emocional que coexiste no combate contra a mutilação do saber, a partir da interaçấo autoeco-organizada, a qual permite uma relação de equidade entre o professor e o aluno. Com efeito, cada professor relata, em suas narrativas, os sentimentos e as expectativas significativas de suas histórias em sala de aula. Para Morin (2011b, p. 102), esse sentimento de doação à missão de ensinar só é possível com o amor, pois "onde não há amor, só há problemas de carreira e de dinheiro para o professor; e de tédio, para os alunos”. Essa interação é evidenciada na fala do professor Entrelaçado:

Certamente, se eu apareci nesta pesquisa foi por estas duas atividades e pelo amor que eu demonstro pela biologia e pela docência, que não são falsos ou artificiais, mas eles emanam de mim porque de fato estou desempenhando a atividade profissional que eu mais gosto e aquela com que sonhei exercer durante boa parte da minha vida.

Tomando essas consideraçóes como mote, o pensamento complexo fornece embasamento para o reconhecimento de que a atividade de ensinar pode acontecer sob formas muito diferentes. Em consequência disso é que afirmamos que o ensino inovador é complexo. Por isso, quando um elemento do sistema didático - professor, aluno, conteúdo, planejamento, entre outros - não consegue integrar as interaçôes que organizam o sistema, há a necessidade de modificá-lo, possibilitando a autorregeneraçáo dos processos de ensino-aprendizagem:

De maneira geral, o estudante chega a uma sala de aula na universidade com uma expectativa, assim como o professor. Romper com estas expectativas, surpreender o estudante com comportamentos e com atitudes faz com que as relaçóes de poder se nivelem a uma altura em que ambos se sentem parte do processo de ensino e voltamos a importância da interação. Nada me dói mais que um estudante com baixo rendimento. Isso não é fracasso dele, mas sim meu enquanto professor que não conseguiu sensibilizá-lo a ponto de que ele se interessasse pelas aulas, pelos conteúdos. Por isso dou muito valor tanto a avaliação de desempenho dos estudantes, como a minh a própria em que eles anonimamente se manifestam acerca das aulas, conteúdos técnicas e demais processos. (Professor Entrelaçado). 
Por meio dessas posturas, a inovação não só tolera a desordem, como também se estrutura a partir das interaçóes (professor-aluno-conteúdoscontexto) que demandam organizações - não estáticas, mas que se movimentam para reorganizar as situaçóes de ensino-aprendizagem. Ou seja, a ordem e a desordem fazem parte da reflexão demandada pela ação. Conforme a narrativa, evidencia-se que "o resultado do processo de ensino nunca é exclusividade do professor ou do estudante, mas sempre representa a interação entre eles, quanto mais bem-sucedida é a interação, mais bem-sucedido é o processo de ensino" (Professor Entrelaçado). Desponta dessa narrativa que os processos de ensino inovador não são unilaterais; pelo contrário, pois

[...] o professor quando ensina não apresenta apenas a informação. Ele seduz a informação. Cria um clima favorável ou não a partir da maneira como apresenta e desenvolve o tema com seus alunos. Através das mais diversas práticas e linguagens comunicativas, o professor reinterpreta os dados da informação e os transforma em mensagem, que vai ser recebida e recodificada diferenciada e individualizada pelos alunos. Não apenas puro saber nem somente sensaçôes, mas um ensemble, um conjunto complexo, em que se misturam raciocínios lógicos, sentimentos, emoçôes e, sobretudo, valores [...] que permanecem agregados às informaçóes apreendidas. (KENSKI, 2001, p. 102).

Pelos fragmentos narrados, percebemos que o ensinar se transforma e, intencionalmente, encaminha o aluno a pensar em outras possibilidades. O professor inovador coloca em movimento as interaçôes do sistema de ensino, ou seja, não paralisa o ensino em um monólogo sobre o conteúdo, como notamos na fala abaixo:

Cito que, por trabalhar em uma disciplina de metodologia, posso ser considerado inovador porque estrutura minha aula de modo a requisitar que mobilizem muitos conhecimentos teóricos anteriores, para pensarem a metodologia do ensino da matemática. Isso faz com que esses conhecimentos prévios sejam reinterpretados à luz da metodologia, o que atribui maior significado. [...] Em função de todas essas características entendo que minha aula mobiliza o grupo de alunos. Não há como não estar atento. Trago como 
indicador disso a presença quase sempre total dos alunos na aula. (Professor Correntinha).

Cunha (1997, p. 91) aponta, em seus estudos sobre a aula universitária como espaço de inovação, que a produção do conhecimento se faz também pelo ensino porque " $[. .$.$] alcança a produçáo do pensamento, a capacidade$ cognitiva e estética do aprendiz". Na aula universitária, a inovação indica gestão e produção de conhecimento. Por isso, ensinar é uma prática incansável, que instiga o aluno a pensar, a refletir, a criar e a problematizar, conforme o relato de um dos professores:

Em nossas aulas, procurava muito mais do que passarl apresentar metodologias para o ensino de ciências, mas proporcionar que eles/as vivenciassem essas metodologias, a fim de pensar as múltiplas possibilidades para um ensino contextualizado, integrado e relevante [...]. Diante disso, aulas inovadoras são aquelas que trazem novos/outros olhares para aquilo que muitas vezes é dito, pensado, lido e reproduzido durante nossa formação enquanto sujeitos docentes (Professor Bouclé).

Os professores inovadores buscam romper, ao longo de seus percursos didáticos, com o modo de pensar simplificador. Este, em vez de perceber os elos integradores do processo didático, acaba por desajuntá-los e reduzi-los. Desse modo,

[...] uma aula ou um curso é inovador quando ele foge do tradicional, do esperado, do conhecido, daquilo que já é batido, usado há muito tempo. Tem que surpreender. Tem que despertar. Tem que fascinar o grupo. Tem que usar uma estratégia diferente. Abordar de outro ponto de vista. Repensar. Fazer novas conexóes. Explorar o inexplorado. (Professor Jaspé).

Assim, a partir das narrativas, percebemos que o professor inovador expressa um pensamento multidimensional, sendo impossível construir um modelo de ensino inovador replicável, uma vez que não é possível reduzi-lo à dimensão técnica. A inovação no ensino também não é estável porque precisa se auto-eco-reorganizar para manter a coexistência da ordem e da desordem, elementos fundantes do movimento e da metamorfose do sistema de ensino. 


\section{Fios que se unem, interlaçam-se, cruzam-se, enredam-se}

Por meio da pesquisa realizada, foi possível reconhecer alguns elementos presentes na dimensão da reflexão e do sistema didático, a partir das compreensōes dos professores:

Figura 1 - Cosmovisáo do conceito de inovaçáo com base nas compreensóes dos professores

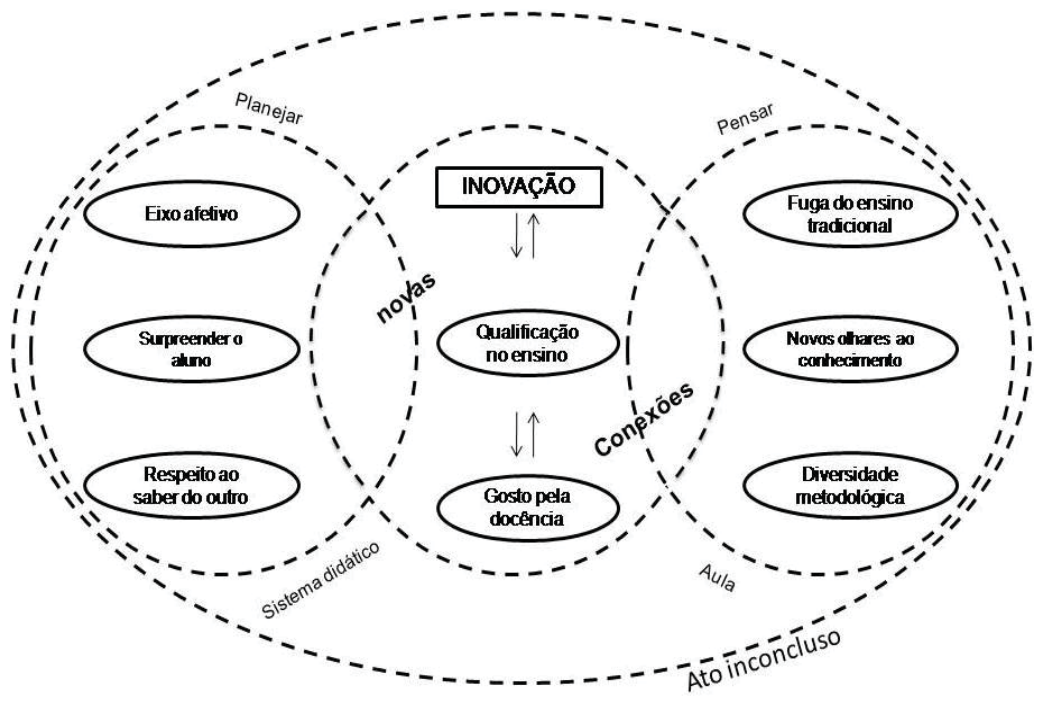

Fonte: Elaborada pelas autoras.

Conforme a Figura 1, o inovar é constituído por elementos organizados por meio de fenômenos complexos. Isso supóe que o papel assumido e as atividades de ensino desenvolvidas pelos professores mostram que a criatividade e a iniciativa são elementos essenciais para a abertura do ensino à inovação. Por isso, o diferencial que entona a inovação está no planejar e no pensar do professor. $\mathrm{O}$ ensino na graduação tem uma função importante com relação à qualificação profissional (teórico-científico-técnico), mas não somente isso, a aproximaçáo humana (o afetivo) também faz parte da apropriação da cultura e do desenvolvimento do pensamento moral e ético do estudante, o que, sem dúvida, é também importante para a sua formação.

Outro ponto importante de sublinhar é que, quando nos remetemos à prática, não queremos homogeneizar o caráter particular que os professores inovadores 
comportam. Conforme explicam Carvalho e Gil-Pérez (2001), são práticas diferentes, conhecimentos científicos e metodológicos distintos. O saber fazer está imbricado no modo em que compreendemos o processo de produção do conhecimento. Mas, o que nos permite traçar essas consideraçōes é que os desassossegos e as vicissitudes sensibilizaram uma leitura do todo, ou seja, ideias sobre o ensino, sem pormenorizar as partes, os conflitos e as estratégias individuais expressas nas narrativas, permitiram a composiçáo de um tecido sobre o ensino inovador.

A partir de narrativas, conseguimos mapear conectores de um interagir, de um retroagir e de um criar que se autoproduzem na aula universitária, gerando a inovação e a possibilidade de boas práticas na Educação Superior. Todos os elementos destacados na análise das narrativas compuseram um emaranhado de fios que cruzam, afastando-se, aproximando-se e unindo-se intencionalmente, apresentando-nos a ordem, a desordem, a organizaçáo e a interaçáo do sistema didático. No sistema da Figura 2, expressamos os elementos que emergiram das narrativas, em cada um dos níveis (bio, sócio, eco) e eixos (cognitivo, epistemológico, estratégico e emocional) de organização. Os fios expressam a interaçấo entre os elementos vinculados aos eixos.

Figura 2 - Cosmovisáo do Ensino Inovador inspirada no Pensamento Complexo

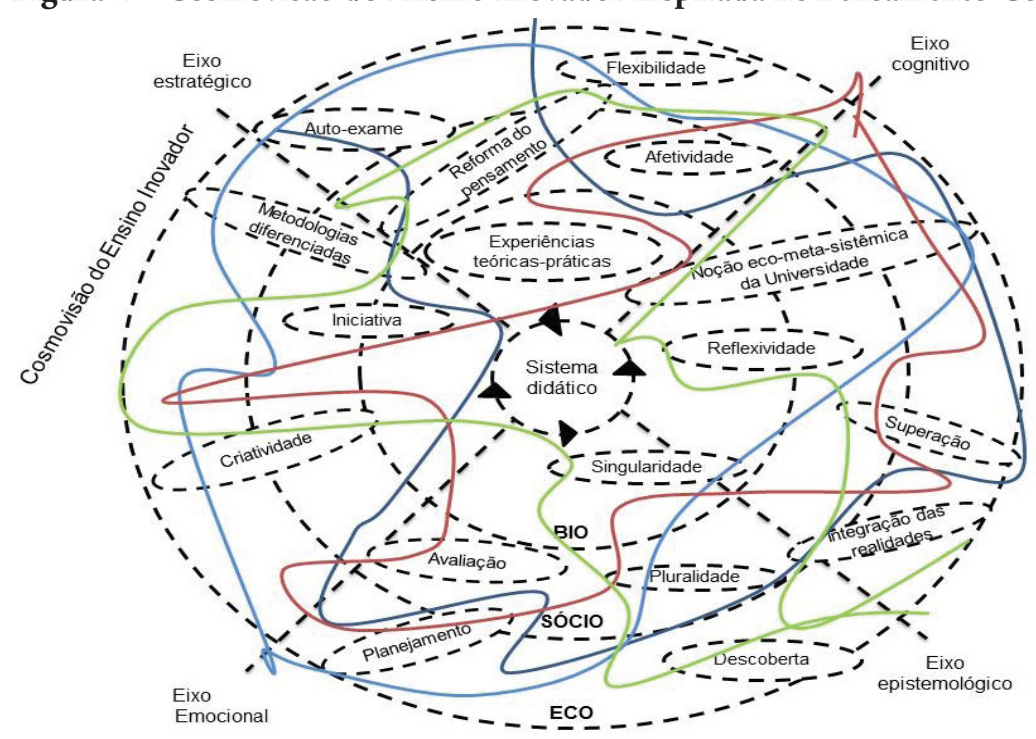

Fonte: Elaborada pelas autoras.

PERSPECTIVA, Florianópolis, v. 31, n. 2, 721-751, maio/ago. 2013

http://www.perspectiva.ufsc.br 
Conforme ilustra a Figura 2, para a efetivação de um ensino inovador, há integração dos saberes para uma compreensão do ensino como uma atividade que necessita de movimento, de interação e de inovação. A possibilidade de um ensino inovador pode iniciar-se por meio das inovaçóes no ensino, como, por exemplo, a adoçẫo de outras formas de avaliação; outras posturas com relação ao conteúdo e à forma de ensinar; o investimento na escuta e na condição dialógica do homem e na recursividade da açáo docente. As narrativas revelam um esforço para a mudança do ensino universitário, manifestando emergências que subsidiaram a criação de quatro princípios de um ensino inovador:

Interaçáo e religaçáo: saber unir e distinguir as diferentes formas de conhecimento; cuidar o outro, dar lugar ao sentir e ao ouvir as subjetividades dos sujeitos; aproximar os saberes visando à interação das Humanidades e as Ciências da Natureza; diminuir as fronteiras conceituais do conhecimento e favorecendo a contextualização do ensino.

Planejamento: saber pensar e planejar de maneira estratégica; incentivar açóes pensantes para o estudante; intencionalidade da ação docente; habilidade de lidar e conviver com a incerteza; retroagir com as suas experiências teóricopráticas de vivências anteriores e compreender que toda a ação é gerativa e com certo nível de biodegradabilidade.

Ação estratégica: organizar a ação pedagógica em função das aprendizagens, docente e discente; ancorar o processo de ensino em uma postura epistemologicamente curiosa; experimentar outras estratégias e abordagens teórico-metodológicas; apropriar-se e apoiar-se propositivamente nas diferenças socioculturais que integram a diversidade do sistema didático e de ensino.

Auto-hetero-avaliaçáo: reconhecer que autonomia pedagógica é alcançada quando o professor reconhece, por meio de suas errâncias, as necessidades e as coerçóes para atividade do ensino; praticar a auto-heteroavaliação, de forma permanente e como reguladora dos processos de ensinoaprendizagem.

Com base nesses princípios, apresentamos nosso último argumento: o professor, ao ensinar, percorre diversos caminhos. Com isso, utiliza-se de diferentes métodos, artefatos, modelos, entre outras possibilidades didáticas que contribuem para a auto-eco-produção da inovação. O ensino inovador tem uma tessitura compartilhada, que nos possibilitou a articulação de quatro princípios. No entanto, estes estão permeados por outras complexidades, 
particularidades e imprevisibilidades. Por essa razão, o pensamento complexo auxilia-nos a apontar possibilidades epistemológicas para uma regeneração do ensino. As inovaçôes no ensino, narradas neste artigo, estão sustentando outras tessituras e nos apresentando outra ecologia da ação docente.

\section{Notas}

1 O conceito de multirreferencialidade foi criado pelo francês Jacques Ardoino. A multirreferencialidade propóe uma leitura plural para a Educação, ultrapassando as barreiras disciplinares, ao perceber, sem discriminar ou reduzir, as diferenças e as semelhanças entre todos os fenômenos estudados (MARTINS, 1998).

2 Morosini (1997), Veiga (2000, 2003), Cunha (1997, 2001a, 2001b, 2005), entre outros.

3 Agradecimentos: CAPES.

$4 \mathrm{Ou}$ seja, ele não é um sujeito determinado por uma única referência.

5 A estratégia, na perspectiva da complexidade, refere-se aos recursos organizadores do pensamento (MORIN, 2005).

\section{REFERÊNCIAS}

CARBONELL, Jaume. A aventura de inovar: a mudança na escola. Tradução de Fátima Murad. Porto Alegre: Artmed, 2002.

CARVALHO, Anna Maria Pessoa de; GIL-PÉREZ, Daniel. Formação de professores de ciências: tendências e inovaçóes. 10. ed. São Paulo: Cortez, 2011.

CASTRO, Amélia Domingues de. O ensino: objetivo da didática. In: CASTRO, Amélia Domingues de; CARVALHO, Anna Maria Pessoa de (Org.). Ensinar a ensinar didática para escola fundamental e média. São Paulo: Cengage Learning, 2001. p. 13-29.

CHRISTENSEN, Clayton M.; HORN, Michael B.; JOHNSON, Curtis W. Inovação na sala de aula: como a inovação de ruptura muda a forma de aprender. Tradução de Raul Rubenich. Porto Alegre: Bookman, 2012.

CLANDININ, Jean; CONNELLY, Michael. Narrative inquiry: experience and story in qualitative research. California: Jossey-Bass, 2000. 
CONNELLY, Michael; CLANDININ, Jean. Relatos de experiencia e investigación narrativa. In: LARROSA, Jorge (Org.). Déjame que te cuente: ensayos sobre narrativa y educación. Barcelona: Laertes, 1995. p. 11-59.

CORDEIRO, Jaime. Didática. 2. ed. São Paulo: Contexto, 2010.

CUNHA, Maria Isabel da. Aula universitária: inovação e pesquisa. In: LEITE, D.; MOROSINI, Marília (Org.). Universidade Futurante: produção do ensino e inovaçẫo. Campinas, SP: Papirus, 1997. p. 79-94.

CUNHA, Maria Isabel da. Inovaçôes pedagógicas na formação inicial de professores. In: FERNANDES, C. M. B.; GRILLO, Marlene. (Org.). Educação Superior: travessias e atravessamentos. Canoas, RS: ULBRA, 2001. p. 33-90.

CUNHA, Maria Isabel da. Inovaçóes: conceitos e práticas. In: CASTANHO, S.; CASTANHO, M. E. L. M. (Org.). Temas e textos em metodologia do ensino superior. Campinas, SP: Papirus, 2001. p. 125-137.

CUNHA, Maria Isabel da. Sala de aula: espaço de inovaçōes e formação docente. In: ENRICONE, Délcia; GRILLO, Marlene (Org.). Educação Superior: vivências e visão de futuro. Porto Alegre: EDIPUCRS, 2005. p.71-82.

ENRICONE, Délcia; GRILLO, Marlene (Org.). Educação superior: vivências e visão de futuro. Porto Alegre: EDIPUCRS, 2005.

FARIAS, Isabel Maria Sabino. Inovação, mudança e cultura docente. Brasília: Liberlivro, 2006.

FERRETTI, Celso João. A inovação na perspectiva pedagógica. In: GARCIA, Walter E. (Org.). Inovação educacional no Brasil: problemas e perspectivas. São Paulo: Cortez, 1980. p. 55-82.

FRANCO, Maria Estela Dal Pai; MOROSINI, Marília. UFRGS: da universidade técnica à universidade inovadora. In: MOROSINI, Marília (Org.). A universidade no Brasil: concepções e modelos. Brasília: INEP, 2006. p. 103-121.

GARCIA, Walter E. Legislação e inovação educacional a partir de 1930. In: GARCIA, Walter E. (Org.). Inovação educacional no Brasil: problemas e perspectivas. São Paulo: Cortez, 1980. p. 205-234.

FULLAN, Michael G.; HARGREAVES, Andy. A escola como organização aprendente: buscando uma educação de qualidade. Porto Alegre: Artmed, 2000.

HASSENFORDER, Jean. A inovação do Ensino. Lisboa: Livros horizonte, 1974. HERNANDEZ, Fernando (Org.). Aprendendo com as inovaçôes nas escolas. Porto Alegre: Artes Médicas, 2000. 
HUBERMAN, A. M. Como se realizam as mudanças em educação: subsídios para o estudo da inovação. São Paulo: Cultrix, 1973.

ISAIA, Silvia M. A. Professor no ensino superior: tramas na tessitura. In: MOROSINI, Marlene C. Enciclopédia de pedagogia universitária. Porto Alegre: FAPERGS/RIES, 2003. p. 241-252.

KENSKI, Vani Moreira. O papel do professor na sociedade digital. In: CASTRO, Amélia Domingues de; CARVALHO, Anna Maria Pessoa de (Org.). Ensinar a ensinar didática para escola fundamental e média. São Paulo: Cengage Learning, 2001. p. 95-106.

KRASILCHIK, Myriam Inovação no ensino de ciências. In: GARCIA, Walter E. (Org.). Inovaçâa educacional no Brasil: problemas e perspectivas. São Paulo: Cortez, 1980. p. 164-182.

LABURÚ, Carlos Eeduardo; MAMPRIN, Maria Imaculada L.; SALVADEGO, Wanda Naves Cocco. Professor das Ciências Naturais e a prática de atividades experimentais no Ensino Médio: uma análise segundo Charlot. Londrina: EDUEL, 2011.

LARROSA, Jorge. Narrativa, identidad y desidentificación. In.: LARROSA, Jorge. La experiencia de la lectura. Barcelona: Laertes, 1996. p. 461-482.

LUCARELLI, Elisa. Desafio institucional: inovação e formação pedagógica do docente universitário. In: CASTANHO, S.; CASTANHO, M. E. L. M.(Org.). O que há de novo na educação superior: do projeto pedagógico a prática transformadora. Campinas, SP: Papirus, 2000. p. 61-74.

LUCARELLI, Elisa. Las práticas inovadoras en el aula universitária: una mirada desde la investigación. In: ZANCHET, B. M. B. A.; GHIGGI, G. Práticas inovadoras na sala de aula universitária: possibilidades, desafios e perspectivas. São Luis, MA: EDUFMA, 2009. p. 17-46.

LÜDKE, M.; SALLES, M. M. Q. P. Avaliação da aprendizagem na Educação Superior. In: LEITE, D.; MOROSINI, Marília (Org.). Universidade Futurante: produção do ensino e inovação. Campinas, SP: Papirus, 1997. p. 169-200.

MACEDO, Roberto Sidnei. Compreender para mediar a formação: o fundante da educação. Brasília: Liberlivro, 2010.

MARTINS, João Batista. Multirreferencialidade e Educação. In: BARBOSA, J. (Coord.). Reflexóes em torno da abordagem multirreferencial. Sáo Carlos, SP: EdUFSCar, 1998. p. 21-33. 
MASETTO, Marcos Tarciso. Inovação na aula universitária: espaço de pesquisa, construção de conhecimento interdisciplinar, espaço de aprendizagem e tecnologias da comunicação. Perspectiva, Florianópolis, SC, v. 29, n. 2, p. 597-620, jul./dez. 2011. Disponível em: <http:// www.periodicos.ufsc.br/index.php/perspectiva/article/view/2175795X.2011v29n2p597/22219>. Acesso em: ago. 2012.

MASETTO, Marcos Tarciso. Inovação na Educação Superior. Interface: Comunicação, Saúde, Educação, Botucatu, SP, v. 8, n. 14, p. 197-202, set./ fev. 2004. Disponível em: <http://www.scielo.br/scielo.php?pid=S141432832004000100018\&script=sci_arttext $>$. Acesso em: ago. 2012.

MORIN, Edgar. A religação dos saberes: o desafio do século XXI. São Paulo: Bertrand Brasil, 2004.

MORIN, Edgar. Ciência com consciência. Tradução de Maria D. Alexandre e Maria Alice Sampaio Dória. 8. ed. Rio de Janeiro: Bertrand Brasil, 2005.

MORIN, Edgar. Introdução ao pensamento complexo. Tradução de Eliane Lisboa. 3. ed. Porto Alegre: Sulina, 2007.

MORIN, Edgar. $O$ método 1: a natureza da natureza. 2. ed. Porto Alegre: Sulina, 2008.

MORIN, Edgar. A minha mão esquerda. Tradução de Edgar de Assis Carvalho e Mariza Perassi Bosco. Porto Alegre: Sulina, 2011a.

MORIN, Edgar. Cabeça bem-feita: repensar a reforma, reformar o pensamento. Tradução de Eloá Jacobina. 19. ed. Rio de Janeiro: Bertrand, 2011 b.

MORIN, Edgar; CIURANA, Emilio-Roger; MOTTA Raul. Educar na era planetária: o pensamento complexo como Método de aprendizagem no erro e na incerteza humana. São Paulo: Cortez; Brasília, DF: UNESCO, 2003.

MOROSINI, Marlene. Autonomia acadêmica, prática pedagógica e controle do conhecimento. In: LEITE, D.; MOROSINI, Marlene (Org.). Universidade Futurante: produção do ensino e inovação. Campinas, SP: Papirus, 1997. p. 95-124.

MURILLO, Javier. A qualificação da escola: conceito e caracterização. In: MURILLO, Javier; MUÑOZ-REPISO, Mercedes (Org.). A qualificação da escola: um novo enfoque. Tradução de Naíla Tosca de Freitas. Porto Alegre: Artmed, 2007. p. 15-43. 
OLIVEIRA, Valeska Fortes. Professor do ensino superior, saberes acadêmicos e demandas profissionais. In: MOROSINI, Marlene. Enciclopédia de pedagogia universitária. Porto Alegre: FAPERGS/RIES, 2003. p. 253-262.

PEIXOTO, Maria do Carmo Lacerda. Apresentação. In: DALBEN, Ângela I. Loureiro Freitas. Convergências e tensóes no campo da formação e do trabalho docente. Belo Horizonte: Autêntica, 2010. p. 520-528.

PÉREZ GÓMES, Angel. O pensamento prático do professor: a formação do professor como profissional reflexivo. In: NÓVOA, António (Org.). Os professores e sua formação. Lisboa: Publicaçóes Dom Quixote, 1995. p. 77-91.

PIMENTA, Selma Garrido. Formação de professores: saberes da docência e identidade do professor. Nuances: estudos sobre educação, São Paulo, v. 3, p. 5-14, 1997.

PRIGOGINE, Ilya. O fim das certezas: tempo, caos e as leis da natureza. Tradução de Roberto Leal Ferreira. São Paulo: Editora da Unesp, 1996.

RASCO, José Felix. A. Inovação, universidade e sociedade. In: CASTANHO, S.; CASTANHO, M. E. L. M. (Org.). O que há de novo na educação superior: do projeto pedagógico a prática transformadora. Campinas, SP: Papirus, 2000. p. 13-60.

SANTOS, Boaventura de Sousa. A crítica da Razão Indolente: contra o desperdício da experiência. 4. ed. São Paulo: Cortez, 2002.

SANTOS, Boaventura de Sousa. Discurso sobre as ciências. 14. ed. Porto: Afrontamento, 2003.

SUÁREZ, Daniel; OCHOA, Liliana; DÁVILA, Paula. Manual de capacitación sobre registro y sistematización de experiencias pedagógicas. Buenos Aires: MECYT/OEA, 2004.

TELLES, Joaô A. “É pesquisa, é? Ah, não quero, não, bem!" Sobre pesquisa acadêmica e sua relação com a prática do professor de línguas. Linguagem \& Ensino, Pelotas, RS, v. 5, n. 2, p. 91-116, 2002.

THURLER, Mônica Gather. Inovar no interior da escola. Porto Alegre: Artmed, 2001.

VEIGA, Ilma Passos Alencastro. Projeto Político-Pedagógico: continuidade ou transgressão para acertar? In: CASTANHO, S.; CASTANHO, M. E. L. M. (Org.). O que há de novo na educação superior: do projeto pedagógico a prática transformadora. Campinas, SP: Papirus, 2000. p. 183-219. 
VEIGA, Ilma Passos Alencastro. Inovaçóes e projeto político-pedagógico: uma relação regulatória ou emancipatória? Caderno Cedes, Campinas, SP, v. 23, n. 61, p. 267-281, dez. 2003. Disponível em: <http://www.scielo.br/pdf/ ccedes/v23n61/a02v2361.pdf>. Acesso em: ago. 2012.

ZANCHET, Beatriz Maria. (Org.). Prática pedagógica no ensino médio: a possibilidade de inovação na perspectiva da emancipação. São Luis,MA: EDUFMA, 2009. 


\section{Enseignement innovateur à I'université: parcours et principes organisateurs}

\section{Résumé}

Cette article discute les expériences, les possibilités et les principes de l'innovation dans l'enseignement universitaire. Pour cela, on a fait des recherches sur ce qu'on comprend comme innovation dans les practiques d'enseignement de six professeurs en travaillant en cours de licence dans le domaine des Sciences de la Nature (Sciences Biologiques et Physique) et dans le domaine de la Pédagogie d'une université au sud du Rio Grande do Sul. La méthodologie élue a été la recherche narrative, car elle prétend, dans ses bases, la compréhension de l'action de formation. À partir des analyses, l'étude montre que la possibilité d'un enseignement innovateur commence par les innovations dans l'enseignement. Les narratives révèlent un effort pour modifier l'enseignement universitaire, en manifestant des urgences qui ont subventionné la création de quatre principes d'un enseignement innovateur: l'interaction et la reliaison ; la planification ; l'action stratégique et l'auto-hétéro-évaluation.

Mots-clés: Éducation pour l'innovation. Enseignement. Complextité.

\section{Innovative teaching at college: trajectory and organizing principles}

\section{Abstract}

This article discusses the experiences, opportunities and principles of innovation in higher education. So we investigated the understandings about innovations and teaching practices of six teachers that work on the field of Natural Science (Biological Sciences and Physics) and Pedagogy at a university in the southern state of Rio Grande do Sul, through the methodology of narrative inquiry.. This strategy was chosen because it aims in its databases to understand the teaching action. Analyzing the results, we conclude that the possibility of an innovative education begins through innovations in teaching. The narratives reveal an effort to change the university teaching, expressing emergencies that supported the creation of four principles of an innovative education: Interaction and rewiring, the planning, strategic action and self-hetero- evaluation.

Keywords: Education for innovation. Teaching profession. Complexity. 


\section{Gionara Tauchen}

E-mail:gionaratauchen@furg.br

\section{Daniele Simóes Borges}

E-mail: daniele.uab@gmail.com

Recebido em: 2/2/2013

Versão final recebida em: 20/5/2013

Aprovado em: 22/5/2013 